\title{
RED FOX FAMILIES OVERLOOK FARMYARD POULTRY AS A FOOD SOURCE
}

\author{
LLOYD S. SAUL, P.O. Box 154, Semans, Saskatchewan. SOA 3 S0
}

Throughout my teens, I was led to believe that wild canines were not to be fully trusted where poultry were involved. However, a fox family that lives in our pasture convinced me that wild animals may live harmoniously with man providing the conditions are suitable. I have learned as a science student that if we are going to live in a world of nature, we will have to be as one. In my endeavor to study this interesting trait of the fox family I had to ward off killing the foxes when the first sign of a predator prey relationshp arose. Killing predators should be the last, not the first, line of attack.' However, thoughts of one day waking up and finding all my chickens gone were soon eroded by the foxes' interesting behavior.

An expectant vixen made a den 210 yards away from the farmyard. She gave birth to six pups in late spring 1980 , and four pups in 1981. Just about the same time (in both years) I purchased chicks to add to the supply of hens and fryers needed to furnish our egg and meat demands. The unique part of all this was that as the fox families grew and hunted together not once did they hinder or kill one of our fowl. In fact, the foxes seemed totally disinclined to attack our free roaming birds.

At first the potential hazard the foxes imposed left me on edge, but as the summer days wore on their behavior stirred my interest. I wondered what inhibited the foxes from utilizing the poultry as a food source. On one occasion the mother fox placidly strolled through the flock enroute to search for ground squirrels in our pasture. She merely glanced at the nearby chickens as she went by them. This opportunity could have provided her with a free meal, but she passed it by. On another day in late summer 1980, the mother and one pup attempted to capture a magpie sitting on a strawpile. The stalking was a failure as the magpie was warned by its mate and flew away. The foxes lay down on the straw for about 15 minutes looking quite gaunt, while a number of chickens were within jumping distance. A count of the fowl showed the fox was not taking them.

Several other neighbors have commented to me that they have had foxes living close to their farms but received no trouble from them. One neighbor saw a fox lie down in the middle of a flock of chickens. Many reasons may be the cause of this behavior. For example the White-tailed Jack Rabbits have almost reached their cyclic plateau. With this high population of rabbits the foxes' food requirements are probably satisfied. Possibly the mother fox had had a previous encounter with a farmyard situation which may have turned out to be a painful one. If this is not the case, then the foxes' ignorance of chickens as food remains a mystery. Whatever the reasons that granted our pasture with this lovely and friendly wildlife neighbor, I'm most grateful.

IPAGE. R. 1974. Do predators have rights? Blue Jay 32(1):51-54. 